Fanum

Sociológico

\section{Forum Sociológico}

Série II

$22 \mid 2012$

Saúde e multiculturalidade

\title{
Avaliando as boas práticas em saúde e migrações em Portugal: teoria, prática e política
}

Beatriz Padilla, Sonia Hernández-Plaza e Alejandra Ortiz

\section{(2) OpenEdition \\ 1 Journals}

Edição electrónica

URL: https://journals.openedition.org/sociologico/550

DOI: 10.4000/sociologico.550

ISSN: 2182-7427

Editora

CICS.NOVA - Centro Interdisciplinar de Ciências Sociais da Universidade Nova de Lisboa

\section{Edição impressa}

Paginação: 33-41

ISSN: 0872-8380

\section{Refêrencia eletrónica}

Beatriz Padilla, Sonia Hernández-Plaza e Alejandra Ortiz, «Avaliando as boas práticas em saúde e migrações em Portugal: teoria, prática e política», Forum Sociológico [Online], 22 | 2012, posto online no dia 26 fevereiro 2013, consultado o 29 março 2022. URL: http://journals.openedition.org/ sociologico/550 ; DOI: https://doi.org/10.4000/sociologico.550

Este documento foi criado de forma automática no dia 29 março 2022.

(c) CICS.NOVA 


\title{
Avaliando as boas práticas em saúde e migrações em Portugal: teoria, prática e política ${ }^{1}$
}

\author{
Beatriz Padilla, Sonia Hernández-Plaza e Alejandra Ortiz
}

\section{Introdução}

$1 \quad 0$ recurso às boas práticas tem-se tornado uma moda que as transformou numa abordagem quase obrigatória no estudo das políticas públicas e privadas. Assim, são hoje um modelo imperativo de análise na investigação científica, ao mesmo tempo fomentado pelas agências financiadoras que procuram ressaltar os casos de sucesso.

2 Há já alguns anos que a utilização das boas práticas tem caracterizado produção de relatórios europeus, nacionais e locais, guias, projetos de investigação, prémios e o reconhecimento de programas específicos e de políticas. Pretende-se com isso identificar modelos desejáveis de ação a seguir e/ou imitar. Consequentemente, o caso das boas práticas, se olhado com reflexividade, deve ser uma chamada de atenção, uma vez que a deliberada busca de um "modelo a seguir" não é nova e nem sempre tem conduzido a bons resultados, especialmente quando os modelos são importados e/ou descontextualizados.

3 Sendo assim, a discussão sobre as boas práticas deve necessariamente ser examinada em termos concetuais, teóricos e práticos, já que a sua repetida utilização enquanto paradigma recomendado pode levar a uma desacreditação do próprio recurso, bem como a uma aceitação acrítica da sua potencialidade.

4 É interessante observar como o uso e abuso das boas práticas não tem sido acompanhado de um desenvolvimento e aprofundamento simultâneo da metodologia, ou seja, de uma melhor definição sobre o que é uma boa prática, como avaliá-la e como, caso convenha, disseminá-la. Em 2007, trabalhou-se na identificação de modelos e casos de boas práticas no âmbito da saúde e das migrações (Padilla et al., 2009) tentando identificar-se intervenções de sucesso a nível dos Estados-Membros da União Europeia. 
$\mathrm{Na}$ altura a perceção, validação e avaliação da prática em si tinha contudo uma componente política devido ao caráter político do evento (Presidência Portuguesa do Conselho da União Europeia). Apesar disso, significou um grande esforço na recolha de bons exemplos numa tentativa de mostrar uma variedade de intervenções percebidas como positivas.

Desde essa data, a incorporação de exemplos de boas práticas ganharam ainda mais importância nos projectos financiados pela Comissão Europeia, tanto na saúde como em outros campos. Na actualidade muitos dos projetos tentam fazer referências, propor ou analisar boas práticas, sem que haja um debate aprofundado sobre as virtudes teóricas e práticas. Muitas vezes as boas práticas acabam por identificar "boas" pessoas e "boas" organizações, e até "boas" intenções, não transcendendo o nível descritivo, o que impossibilita alcançar elaborações de caráter reflexivo e analítico.

6 Uma primeira evolução nesta metodologia e abordagem, já assinalada em Padilla e Portugal (2007), deu-se ao nível da denominação. Passou-se da ideia de melhores práticas (best practice) para boas práticas (good practice), devido à ideia incorreta de hierarquia que distinguia a noção superlativa de "melhor". 0 adjetivo "boa" em si apresenta duas vantagens: por um lado admite a existência de uma diversidade de formas e modelos de ação, de fazer bem as coisas, e, por outro, sugere que a construção do modelo de acção se realiza de baixo para cima, sendo assim mais democrático e participativo. Esta visão é uma nova reflexão sobre as boas práticas, que assinala a relevância da forma como uma prática é concebida e percebida.

\section{Boas práticas}

7 É comum encontrar muitas referências às boas práticas como autoexplicativas, sem aprofundar o seu significado e denominação. Em 2004, Aspinall e Jacobson, num relatório inovador para o Reino Unido, destacaram a importância da identificação de boas práticas como forma de equilibrar as disparidades étnicas na saúde e nos cuidados de saúde, tendo em conta pela primeira vez a situação dos imigrantes e minorias étnicas. Se bem fazem referência às qualidades e às características desejáveis como práticas, não só não definem o conceito, mas este é encarado como um dado adquirido. Resultado, a boa prática nunca é definida como tal. o relatório assume ainda, como um dado adquirido e como ponto de partida, que as boas práticas se apoiam nos cuidados culturalmente apropriados, não chegando contudo a debater o que significa culturalmente apropriados. Ou seja, o relatório resulta duplamente enviesado por partir de dados adquiridos não questionados, embora os autores atuem de boa fé.

8 Também em 2004, Stegeman e Costongs, num relatório europeu intitulado Promovendo a inclusão social e combatendo as disparidades em saúde na Europa - Uma revisão das boas práticas no campo da saúde, identificaram boas práticas, no âmbito geral da Estratégia de Lisboa, com o intuito de fornecer aos técnicos e políticos que trabalham nas políticas de saúde e sociais novas ideias para promover a inclusão social. Nessa ocasião, as boas práticas foram definidas como "projetos ou programas que podiam ser ilustrados, quando possível, com informação sobre as políticas relacionadas e sustentadoras dessas intervenções. Estes projetos ou programas deviam estar a ser implementados ou ter sido implementados até há dois anos, e demonstrado terem sido inovadores e/ou particularmente efetivos" (Stegeman e Costongs, 2004: 11). Neste caso, as organizadoras, para serem mais inclusivas, decidiram ser flexíveis quanto ao tema da 
avaliação, sendo que a falta de avaliação não deixaria contudo de fora os exemplos de boas práticas. Neste sentido identificaram 52 casos de boas práticas que incluíam um conjunto muito abrangente e variado de programas e projetos, muitos deles concebidos para populações e grupos-alvo específicos. As autoras concluíram que, embora as boas práticas fossem muito diferentes em termos de natureza, alcance e escala, a maior parte delas adotara princípios centrais comuns que direta ou indiretamente atingem o problema da exclusão social. Estes princípios sugeridos são apresentados na Tabela 1, sendo útil a sua aplicação com as populações migrantes, na redução das disparidades em saúde.

Tabela 1 㡠 Metodologias gerais do âmbito da saúde que promovem a inclusão social

\begin{tabular}{|c|c|}
\hline $\begin{array}{c}\text { Estilos de Vida } \\
\text { Saudável }\end{array}$ & $\begin{array}{l}\text { Alimentação saudável } \\
\text { Atividades físicas } \\
\text { Gestão do streess. } \\
\text { Prevenção de adições (álcool e } \\
\text { drogas) } \\
\text { Saúde sexual }\end{array}$ \\
\hline Empoderamento & $\begin{array}{l}\text { Participação ativa da população-alvo } \\
\text { Formação (educativa e no trabalho) } \\
\text { Dar emprego à própria população- } \\
\text { alvo } \\
\text { Facilitação de grupos de auto-apoio. }\end{array}$ \\
\hline Capital Social & $\begin{array}{l}\text { Expansão das redes sociais } \\
\text { Utilização de metodologias de parti- } \\
\text { cipacãa comunitária }\end{array}$ \\
\hline
\end{tabular}

FONTE: Elaboração própria baseada em Stegeman e Costongs, 2004.

Um relatório da União Europeia de 2008 intitulado Qualidade e Equidade no Acesso aos Serviços de Saúde traz algumas conclusões importantes na discussão sobre as boas práticas, salientando alguns elementos positivos comuns. Entre as mais importantes figuram: as intervenções que promovem as parcerias com a sociedade civil e que implicam diferentes níveis de intervenção, a estratégia para envolver as próprias populações migrantes no apoio aos migrantes (MiMi - with Migrants for Migrants), a importância de definir algumas populações mais vulneráveis como alvo (refugiados e requerentes de asilo e a população roma), a relevância das ações de promoção da saúde como prevenção da exclusão, e a integração de serviços de saúde e sociais ou serviços integrados.

Apesar de concordarmos com a maioria dos aspetos salientados pelos autores citados, optamos por adotar uma visão crítica sobre as boas práticas, não com o intuito de desmerecer os seus contributos, mas sim para estimular o debate mais aprofundado sobre o tema, rejeitando os factos adquiridos. Neste sentido, concordamos com Ingleby (WHO, 2010) quando afirma que as boas práticas são formas de remediar os problemas existentes. Inferimos aqui que elas não devem ser o objetivo das políticas e intervenções em saúde, mas que tê-las presentes no momento da planificação e conceção de políticas ajuda a saber em que sentido devemos avançar, se olhando para o futuro, para corrigir os problemas detetados. O mesmo autor assinala quatro estratégias positivas para melhorar os serviços: formação dos recursos humanos, diversificação da força de trabalho, utilização de mediadores culturais e adaptação de 
protocolo, procedimentos e tratamentos (WHO, 2010). Finalmente, reiteramos o que foi salientado em Padilla et al. (2009), a importância de explicitar os valores que sustentam as intervenções antes de proceder à sua avaliação.

\section{Valores e poder na avaliação das boas práticas em saúde e migrações}

11 Uma questão central na avaliação de intervenções (que possam vir a ser boas práticas) é a que se prende com o papel dos valores e das dinâmicas de poder. Qualquer programa de intervenção no âmbito da saúde com populações imigrantes está impregnado de valores: os valores implícitos e/ou explícitos nas políticas de saúde e imigração; os valores dos agentes implicados na planificação das intervenções; os valores dos profissionais responsáveis pela sua implementação e a sociedade no seu conjunto. Todos eles influem no modo como se definem os problemas objeto de intervenção, nas necessidades identificadas como prioritárias, na formulação de objetivos, na seleção das estratégias de intervenção e na relação entre os profissionais (da saúde, do serviço social, etc.) e a população-alvo.

12 Por outro lado, enquanto atividade valorativa, a identificação de boas práticas consiste em emitir juízos de valor acerca do que é "bom" e do que é "mau", pelo que se torna fundamental explicitar claramente esses valores. A maior parte dos projetos sobre a avaliação de boas práticas em matéria de saúde e imigração deixa contudo de lado essa questão, correndo o risco de aceitar que as intervenções neste âmbito, e a própria atividade de identificação e avaliação das boas práticas, se encontram isentas de valores.

13 No que diz respeito ao papel das dinâmicas de poder, uma vasta evidência empírica mostra a existência de grandes desigualdades no estado da saúde, bem como no acesso à qualidade dos serviços de saúde nas populações imigrantes, existindo uma evidente assimetria em relação à população autóctone. Em geral, os imigrantes costumam apresentar níveis inferiores de saúde, menor acesso aos serviços de saúde, recebendo cuidados de saúde de pior qualidade (WHO, 2010). Neste sentido, a Comissão sobre os Determinantes Sociais da Saúde (CSDH, 2008) da Organização Mundial da Saúde (OMS) sublinhou que os processos de exclusão social são a principal causa das desigualdades na saúde nas populações migrantes e minorias étnicas.

Torna-se particularmente clara a definição apresentada pela Rede de Conhecimento sobre Exclusão Social da Comissão sobre os Determinantes Sociais da Saúde da OMS, segundo a qual: "a exclusão consiste numa série de processos dinâmicos e multidimensionais, estritamente relacionados com as relações desiguais de poder que interagem à volta de quatro dimensões principais - económica, política, social e cultural - e a diferentes níveis, incluindo o individual, familiar, comunitário, nacional e global. o resultado dos ditos processos é um contínuo de inclusão/exclusão caracterizado por um acesso desigual aos recursos, capacidades e direitos, o que conduz às desigualdades na saúde" (SEKN, 2008: 2). Como consequência, "as iniciativas orientadas para a promoção da equidade na saúde de migrantes e minorias étnicas deveriam incluir-se integralmente nas campanhas sobre desigualdades socioeconómicas na saúde", dada a estreita relação que existe entre a saúde e a exclusão social nestas e noutras populações vulneráveis (WHO, 2010: 24). 
15 A intervenção e avaliação das boas práticas em termos de saúde e imigração não são alheias às dinâmicas de poder entre os diferentes atores implicados (profissionais da saúde, imigrantes, mediadores interculturais, trabalhadores sociais, responsáveis políticos, organizações não governamentais (ONG), associações de imigrantes, investigadores, instituições de financiamento, etc.). Um programa de intervenção neste âmbito pode contribuir para a mudança e a transformação das estruturas de poder que perpetuam a exclusão social a diferentes níveis (pessoal, relacional, organizacional, comunitário, socioeconómico, ambiental, político) mas pode contribuir também para a manutenção do statu quo, através da implementação de políticas e práticas que reforçam o acesso desigual aos direitos e recursos necessários para alcançar e manter a saúde.

16 Neste sentido, um critério fundamental na avaliação de intervenções ao nível da saúde e migração, que possam ser consideradas boas práticas é o que se relaciona com o grau em que uma iniciativa, ação ou programa de intervenção tem em consideração o impacto das assimetrias de poder sobre as desigualdades na saúde. 0 dito impacto dá-se a dois níveis: (1) nos problemas e necessidades objeto da intervenção, nos objetivos e ações, no desenho e planificação da intervenção; e (2) nos seus resultados, ou seja, em que medida consegue promover relações de poder mais simétricas de forma a contribuir para a diminuição das desigualdades na saúde, o acesso e a qualidade dos cuidados de saúde.

17 Este critério encontra-se intimamente relacionado com a noção de "validade psicopolítica", introduzida por Isaac Prilleltensky $(2003,2008)$ no seio da psicologia comunitária com o objetivo de destacar o impacto das dinâmicas de poder no bem-estar humano. Segundo Prilleltensky (2008), a validade psicopolítica define-se como o grau em que uma investigação ou uma determinada acção considera o papel das dinâmicas de poder implicadas nos fenómenos objeto de estudo (validade epistémica) bem como o grau em que a dita investigação ou ação contribui para promover o bem-estar através da redução de assimetrias de poder (validade transformadora). Em alternativa à noção referida, propomos utilizar neste trabalho o conceito de validade sociopolítica a fim de ser aplicado de uma forma mais geral no âmbito da intervenção social em saúde e migrações.

\section{Enquadramento institucional e iniciativas de saúde e imigração}

Com o intuito de contribuir para a sistematização crítica da informação sobre o elevado número de intervenções e práticas no âmbito da saúde dos imigrantes em Portugal, especificamente na área da saúde materno-infantil e reprodutiva, realizamos uma compilação das iniciativas/intervenções existentes em Lisboa e arredores (não pretendendo ser um levantamento exaustivo). Neste sentido foram identificados programas e incitativas públicas e privadas, através do estudo de instituições, organizações e associações onde se prestam cuidados no atendimento dos imigrantes no que respeita à saúde, quer de forma geral quer através de atividades específicas. Pretende-se assim identificar as práticas existentes, considerando aspetos políticos, administrativos e metodológicos, para numa fase posterior avaliar em que medida podem ser consideradas intervenções exemplares ou boas práticas. Analisaremos de 
forma pormenorizada um caso paradigmático que tem sido considerado como boa prática: a unidade móvel do Centro de Saúde da Venda Nova, na Amadora.

Um ponto de partida importante no enquadramento institucional é que, a nível internacional, Portugal tem conseguido uma boa qualificação nas práticas de integração social dos imigrantes (MIPEX, 2011). Sem questionar o facto, e sabendo que uma das limitações do MIPEX é o facto de se basear mais nos marcos legislativos e regulamentares do que nas práticas efetivas, devemos aceitar o facto de que Portugal tem sido pioneiro na adoção de intervenções que podem ser consideradas boas práticas em matéria de imigração, tanto no que diz respeito às organizações não governamentais como ao próprio Estado. No entanto, ficaria por avaliar criticamente as iniciativas, já que a referência às boas práticas se tem tornado um fim em si mesmo.

$\mathrm{Na}$ identificação de boas práticas seguiremos em primeiro lugar o modelo sugerido pela UNESCO, que se baseia no caráter inovador, sustentável e replicável das iniciativas, bem como no seu impacto positivo nas pessoas e comunidades envolvidas (Padilla e Portugal, 2007). Importa salientar este último aspeto como sendo um indicador que possibilita avaliar as estratégias de intervenção utilizadas, bem como o seu poder de alcance. Importa ainda referir que as boas práticas, desde a ótica das políticas, promovem a aprendizagem horizontal (Truong, 2006) desempenhando um nexo entre a comunidade, o governo (policy-making) e o sector privado. Assim, a correta coordenação e implantação destas iniciativas permite ainda encontrar sinergias entre os profissionais e a comunidade. Finalmente, acrescentamos que os aspetos relativos aos valores e ao poder são centrais no processo de avaliação das práticas, tal como referimos anteriormente.

Em Portugal, e mais especificamente na Área Metropolitana de Lisboa, existem várias instituições e associações que trabalham com ou tendo em conta a população imigrante no âmbito da saúde. Sem pretender apresentar uma abordagem exaustiva, mencionaremos algumas iniciativas de instituições de caráter público/governamental e outras de caráter associativo como exemplo. Dentro do contexto nacional institucional destaca-se o Alto Comissariado para a Imigração e Diálogo Intercultural, o ex-Alto Comissariado para a Saúde (extinto), as Câmaras Municipais, a Direção-Geral da Saúde, a Ordem dos Enfermeiros, os Centros de Saúde e os Hospitais Públicos. Dentro do universo das intervenções das associações e do terceiro sector, identificamos também várias práticas e entidades. A Tabela 2 sistematiza algumas das principais iniciativas cuja população-alvo abrange as populações desfavorecidas e mais vulneráveis, podendo incluir os imigrantes. 


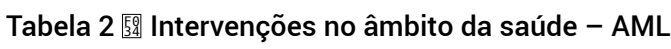

\begin{tabular}{|c|c|}
\hline Âmbito específico de intervenção & Organização e/ou programa ou iniciativa \\
\hline Saúde Materno-infantil & $\begin{array}{l}\text { Ajuda de Mãe (vários projecţ̊s); Banco do Bebé (Maternidade A. da Costa); } \\
\text { Preparação para o Nascimento (C. M. Seixal, C. S. Seixal e C. S. Amora); O } \\
\text { Vigilante; Ajuda de Berço; Projeto Mãe (Associação de Defesa e Apoio da Vida); } \\
\text { Ponto de Apoio à Vida (vários projectoss); Iniciativa Barrigas de Amor (C. M. Oeiras); } \\
\text { Projeto de intervenção comunitária em saúde materno-infantil (C. S. Oeiras); } \\
\text { Projeto de Intervenção comunitária do C. S. Venda Nova, Associação Portuguesa de } \\
\text { Apoio ao Bebé Prematuro; Roteiros da Saúde da Mulher e Infantil da Santa Casa da } \\
\text { Misericórdia; etc. }\end{array}$ \\
\hline Saúde Sexual e Reprodutiva & $\begin{array}{l}\text { Associação para o Planeamento da Família (vários projetos); Mães do Bairro } \\
\text { (Médicos pela escolha); Consulta saúde reprodutiva para jovens da AJPAS; Programa } \\
\text { de educação sexual e planeamento familiar e Chat saúde da C. M. Oeiras; etc. }\end{array}$ \\
\hline Rarentalidade & $\begin{array}{l}\text { Entre pais, entre pares (Casa Seis); Escola para pais da Associação Família e } \\
\text { Sociedade; Workshoph Mães \& Bebés do Centro Comercial Allegro; Programas Pulo e } \\
\text { Caleidoscópio do Moinho da Juventude; etc. }\end{array}$ \\
\hline Apoio Material & $\begin{array}{l}\text { Ajuda de Mãe (vários projetos); O Vigilante; Banco do Bebé; Mungs \& Kids; vários } \\
\text { centros comunitários, associações e paróquias; etc. }\end{array}$ \\
\hline
\end{tabular}

Fonte: ELABORAÇÃo PRÓPRIA

Uma das características comuns e significativas das iniciativas consideradas refere-se ao seu caráter integral, procurando ultrapassar a excessiva ênfase nos aspetos culturais (leia-se essencializantes) da saúde. Neste sentido, privilegiam uma aproximação holística, considerando as populações-alvo, não unicamente no seu caráter imigrante (embora definidos como portadores de uma cultura diferente), mas sim na sua condição de população vulnerável, excluída socialmente. Em consequência, os artífices das intervenções no geral consideram que o estado de saúde é o resultado dos determinantes sociais aos quais estão sujeitos. Em geral estas iniciativas contam com equipas de profissionais de saúde (médicos, enfermeiros, psicólogos e trabalhadores sociais) com formação e experiência em contextos interculturais, sem esquecer outros condicionantes de caráter socioeconómico. Em muitos casos é possível verificar que as intervenções ou programas funcionam em parcerias que tentam orquestrar uma coordenação dos serviços prestados pelo Sistema Nacional de Saúde, quer ao nível do centro de saúde quer do hospital. Algumas das intervenções pretendem ainda socorrer e auxiliar nas situações de maior carência.

\section{Boas práticas no campo da saúde e imigração em Portugal: A Unidade Móvel de Saúde da Venda Nova}

23 A Unidade Móvel de Saúde (UMS) da Venda Nova foi identificada em vários projetos internacionais como boa prática (Machado et al., 2009; Padilla, 2011). Após uma breve descrição da sua história e do seu contexto, examinaremos o grau em que a dita intervenção considera o impacto das assimetrias de poder sobre as desigualdades na saúde, o acesso e a qualidade dos serviços de saúde em diferentes momentos e/ou componentes do programa de intervenção, concretamente: nas necessidades e problemas identificados, na delimitação da população-alvo, na formulação dos objetivos nas ações levadas a cabo e nos resultados da intervenção.

24 a) História e contexto: A UMS da Venda Nova é um programa de intervenção comunitária implementado em 2001 pelo Centro de Saúde da Venda Nova (ACES VII Amadora) nos bairros empobrecidos do concelho da Amadora. A história do projecto 
começa em 1993 com o programa intitulado Saúde no século XXI, cujo objectivo prioritário consistia em reduzir as desigualdades na saúde fazendo-a chegar a populações de difícil acesso localizadas nos bairros periféricos. Neste sentido, parte-se do reconhecimento explícito da existência de desigualdades na saúde que, por serem injustas, devem ser abordadas e diminuídas. Aceita-se que as ditas desigualdades afetam principalmente os grupos que vivem em condições de exclusão social e de marginalização, desigualdades estas ligadas a assimetrias de poder.

b) Avaliação das necessidades: esta atividade, crucial nas etapas iniciais do ciclo de intervenção social, implica emitir juízos de valor sobre os problemas e necessidades que serão objeto de intervenção. Não se trata assim de uma atividade isenta de valores nem alheia às dinâmicas de poder entre os diferentes grupos implicados. Entre as questões que devem ser tidas em conta importa destacar: (1) Em que medida as necessidades identificadas e definidas como prioritárias resultam de dinâmicas assimétricas de poder? A que níveis (social, económico, cultural, político, etc.)? As desigualdades na saúde e no acesso aos cuidados de saúde são o resultado de processos de exclusão social? (2) A avaliação das necessidades utiliza de facto uma aproximação participativa, integrando a perspetiva de todos os grupos implicados? Quem define as necessidades objeto da intervenção? Os profissionais? Os especialistas? A própria comunidade afetada? Os políticos? As necessidades sentidas/percebidas e exprimidas pelos grupos mais vulneráveis são avaliadas? Os métodos de avaliação das necessidades têm em conta as características e condições (sociais, económicas, culturais, educativas, materiais, etc.) do contexto e dos grupos de população implicados? (3) Avaliam-se as potencialidades e recursos da comunidade no que diz respeito à prevenção e promoção da saúde e à redução das desigualdades na saúde e no acesso aos cuidados de saúde?

A UMS da Venda Nova começa pela avaliação das necessidades, dando especial atenção às necessidades sentidas e referidas pela população. Os residentes são em geral jovens, de nível socioeconómico e educativo baixo, muitos deles imigrantes procedentes dos PALOP, alguns em situação irregular. As necessidades prioritárias situam-se na área da saúde materno-infantil: ausência de seguimento regular e controle médico durante a gravidez, verificando-se casos frequentes de mulheres que recorrem pela primeira vez ao centro de saúde/hospital pouco antes do nascimento do bebé ou mesmo no momento do parto; ausência de vacinação regular na infância; número elevado de adolescentes grávidas; acesso limitado aos serviços de planificação familiar e de prevenção de infeções de transmissão sexual. Observa-se ainda uma afluência reduzida às consultas médicas bem como numerosos casos de crianças e adultos não registados neste centro.

O programa pressupõe a existência de uma relação entre necessidades sociais e de saúde, ligando-as às assimetrias de poder que caracterizam a exclusão social. Os diferentes níveis das assimetrias de poder são: (1) socioeconómico: desemprego e emprego precário, problemas económicos (ausência de rendimentos, dificuldades na aquisição de alimentos e medicamentos), incompatibilidade de horários; (2) legal: situação irregular: (3) comunitário: bairros degradados e insalubres, condições precárias de habitação; (4) relacional: violência de género; (5) pessoal: nível educativo baixo, conhecimento limitado acerca dos serviços de saúde, desconhecimento dos direitos de acesso aos cuidados de saúde. Parte-se do princípio de que a natureza multidimensional da exclusão social origina uma realidade complexa e multiproblemática na qual confluem necessidades interdependentes num círculo 
vicioso, o qual limita seriamente as oportunidades de aceder aos cuidados de saúde e alcançar níveis aceitáveis de saúde e bem-estar (Hernández-Plaza et al., 2010).

As necessidades que serão objeto de intervenção são definidas a partir do trabalho diário dos profissionais com a comunidade, tanto na UMS como nas visitas domiciliárias, entrevistas a líderes formais e informais, reuniões com a população e revisão de bibliografia especializada. Esta metodologia permite que os profissionais conheçam de forma direta a cultura, representações, linguagem, hábitos de saúde, terapias tradicionais e outras particularidades da comunidade, criando assim condições adequadas para a prestação de cuidados de saúde culturalmente competentes, baseados no conhecimento e no respeito mútuo.

c) População-alvo: Na delimitação da população à qual será dirigida o programa existem questões que são relevantes quanto ao papel do poder e que são as seguintes: (1) Em que medida inclui os grupos mais vulneráveis e desfavorecidos? (2) Utiliza uma aproximação inclusiva que permita evitar a segregação e que não contribua para a reprodução da marginalização e da exclusão social?

30 A população escolhida inclui todos os residentes nos bairros abrangidos pelo Centro de Saúde da Venda Nova, especialmente mulheres grávidas e crianças. A intervenção utiliza uma aproximação inclusiva, partindo do princípio de que os processos de exclusão social são a principal causa das desigualdades na saúde e no acesso aos serviços de saúde, tanto para imigrantes como nacionais.

31 Este tipo de aproximação é muito relevante e necessária no atual contexto de crise, uma vez que qualquer medida de discriminação positiva dirigida de forma particularmente à população imigrante pode contribuir para aumentar o preconceito e rejeição por parte dos nacionais, resultantes de processos de comparação social a nível intergrupal e a perceção de deprivação relativa. Neste sentido, a adoção de uma abordagem inclusiva e equitativa para tratar as desigualdades na saúde, incorporando tanto a população nacional como a imigrante, torna-se fundamental.

d) Metas e objetivos da intervenção: No que diz respeito ao papel do poder na definição das metas e objetivos da intervenção, devem ser colocadas questões do tipo: (1) As metas e objetivos do programa baseiam-se nas necessidades prioritárias previamente identificadas? (2) A intervenção tem por objetivo reduzir desigualdades na saúde, no acesso e na qualidade dos cuidados de saúde, aceitando que as ditas desigualdades são injustas? A equidade nos cuidados de saúde é uma meta do programa? (3) Pretende-se como objetivo reduzir as assimetrias de poder associadas aos processos de exclusão social? (4) Pretende-se como objetivo o "empoderamento" da comunidade, incluindo os grupos mais vulneráveis? A que níveis? Coloca-se como objetivo promover as potencialidades e recursos da comunidade?

A UMS da Venda Nova tem por objetivos: (1) aumentar o acesso aos cuidados de saúde, atuando como uma ponte entre o centro de saúde e a comunidade; (2) intensificar o seguimento e controle regular durante o período da gravidez; (3) promover a vacinação regular das crianças; (4) melhorar o acesso aos serviços de planeamento familiar; (5) aumentar o seguimento e o controle regular da saúde por parte da população; (6) difundir informação sobre saúde e cuidados de saúde na comunidade; (7) promover a participação da comunidade na prevenção e promoção da saúde; e (8) melhorar a situação social e de saúde da população. Sendo assim, a meta fundamental é a promoção da equidade nos cuidados de saúde, e os objetivos definem-se a partir das necessidades 
detetadas, dando prioridade à saúde materno-infantil como população especialmente vulnerável.

e) Ações do programa: No que diz respeito ao papel das dinâmicas de poder nas ações do programa, colocam-se algumas questões relevantes tais como: (1) A intervenção adota uma abordagem participativa, promovendo a participação ativa da comunidade? (2) As ações são culturalmente apropriadas? Têm em consideração as condições socioeconómicas da população e o contexto objeto da intervenção? (3) Os profissionais do programa estabelecem uma relação simétrica com a comunidade?

As estratégias de intervenção são fundamentalmente três: 1) ação direta nos bairros através da unidade móvel, 2) visitas domiciliárias e 3) educação e promoção da saúde; todas elas apoiadas no trabalho de uma equipa de profissionais formada por três enfermeiras, um/a psicólogo/a, um/a trabalhadora social e pelo condutor da viatura. $\mathrm{Na}$ unidade móvel, os profissionais prestam cuidados de saúde à comunidade, marcam consultas no centro de saúde, iniciam os processos de inscrição no mesmo e derivam a outros serviços e instituições segundo a problemática particular de cada um.

O trabalho da UMS complementa-se com visitas domiciliárias para seguimento dos casos específicos. Paralelamente, os profissionais da unidade móvel participam na vida do bairro, tanto em atividades de prevenção e promoção da saúde (campanhas de vacinação, educação sexual, atividades com grupos específicos como é o caso dos adolescentes, dos idosos, das mães adolescentes, das crianças, pais e educadores nas escolas, etc.) como em eventos sociais, culturais e lúdicos. Assim sendo, estes profissionais trabalham "com" a comunidade e não "para" a comunidade.

Por conseguinte, os princípios que orientam a intervenção são: (1) proximidade: em vez de esperar que a população vá ao centro de saúde, os profissionais levam os cuidados de saúde aos bairros, servindo de ponte com o centro de saúde; (2) simetria na relação entre os profissionais da saúde e a comunidade baseada no conhecimento e respeito mútuo, na confiança, na empatia e na não discriminação (étnica, de género, etc.); (3) continuidade: o programa conta com uma trajetória de dez anos no bairro, apoiado por um grupo de profissionais estável; (4) conhecimento direto dos contextos de vida dos indivíduos.

38 Este tipo de relações entre os profissionais da saúde e os utentes, baseadas na simetria de poder, tornam possível prestar cuidados de saúde culturalmente apropriados. A UMS representa, além do que foi referido, um cenário apropriado para o treino em competências culturais de jovens profissionais, e daí contar com a presença de estudantes das escolas de enfermagem e de Saúde Pública que aí realizam estágios como parte integrante da sua formação, desenvolvendo assim um serviço de extensão. Paralelamente, a intervenção promove o empoderamento da comunidade, principalmente ao difundir informação e conhecimentos sobre saúde, sobre os direitos de acesso e funcionamento do sistema de saúde. Permite ainda uma tomada de consciência sobre os problemas sociais do bairro, favorecendo o fortalecimento das redes sociais e promovendo a participação comunitária.

39 Um aspeto fundamental desta prática é a sua integração dentro do Sistema Nacional de Saúde, tanto no seu funcionamento como no seu financiamento, através do Ministério da Saúde. Deste modo, a intervenção contribui para a promoção de um sistema de saúde baseado na equidade, em consonância com as recomendações da OMS (WHO, 2010), que sugere integrar as iniciativas orientadas para a promoção da saúde dos migrantes e 
minorias étnicas dentro das campanhas gerais contra as desigualdades socioeconómicas da saúde.

Neste sentido, o programa analisado diferencia-se claramente de outras intervenções que deixam a saúde dos imigrantes nas mãos da boa vontade e da solidariedade da sociedade civil, principalmente através das ONG, associações de imigrantes e associações sem fins lucrativos. Apesar da qualidade e da enorme relevância do trabalho habitualmente desenvolvido por este tipo de organizações, a sua principal limitação prende-se com a impossibilidade de garantirem a sustentabilidade da intervenção, uma vez que dependem do voluntariado ou da disponibilidade de financiamento, num âmbito tão fundamental como o da saúde. Apesar disto, a UMS da Venda Nova apresenta a vantagem de ter sido levada a cabo numa parceria com a Câmara Municipal da Amadora, ONG, associações de imigrantes e outras organizações locais, promovendo deste modo a participação comunitária. Cabe destacar a colaboração com a associação AJPAS (Associação de Jovens Promotores da Amadora Saudável), que utiliza a mesma UMS do Ministério da Saúde para prestar cuidados de saúde, a qual foi também caracterizada como boa prática (Fernandes \& Pereira Miguel, 2009).

41 e) Resultados: O objetivo final da avaliação das intervenções deverá ser identificar os programas bem-sucedidos quanto à redução das desigualdades na saúde e no acesso e qualidade dos cuidados de saúde.

42 No que diz respeito ao papel do poder, algumas questões devem ser colocadas: (1) o programa responde eficazmente às necessidades previamente identificadas, incluindo as necessidades dos grupos mais vulneráveis? (2) Consegue reduzir as assimetrias de poder associadas aos processos de exclusão social? (3) Consegue aumentar a equidade nos cuidados de saúde? (4) Consegue promover o empoderamento da comunidade, de forma a incluir os grupos mais vulneráveis? A que níveis? (5) O programa e os seus resultados são sustentáveis? (6) A avaliação dos resultados utiliza uma aproximação participativa de todos os grupos envolvidos? Os métodos de avaliação dos resultados têm em conta as características e condições do contexto e dos grupos de população envolvidos?

43 A avaliação dos resultados da UMS da Venda Nova revela, de forma geral, resultados positivos nas áreas das necessidades previamente identificadas, uma vez que: permite um melhor acesso aos cuidados de saúde, aumenta o seguimento e controle durante o período da gravidez, aumenta a vacinação regular das crianças, melhora o acesso aos serviços de planeamento familiar, aumenta o seguimento regular da saúde, consegue distribuir informação sobre prevenção da doença e promoção da saúde, promove a participação comunitária e melhora a situação social e de saúde da população. A avaliação dos resultados utiliza uma aproximação participativa, compartindo anualmente os resultados com a comunidade e as instituições parceiras.

Até ao momento a sustentabilidade do programa tem-se baseado na sua inclusão dentro do Sistema Nacional de Saúde, em parceria com ONG e associações locais. Não obstante, na atual situação de crise, e quando a própria sustentabilidade do Sistema Nacional de Saúde está em causa, cabe perguntar qual poderá ser o futuro deste tipo de intervenções tão fundamentais na prestação de cuidados de saúde a toda a população, incluindo aos sectores mais vulneráveis. 


\section{Conclusões}

45 As boas práticas têm sido consideradas como uma ferramenta de grande utilidade e relevância, como uma ponte necessária entre a ciência, a prática e o "policymaking" (Chinman et al., 2004; Padilla et al., 2009). Contudo não têm sido suficientemente debatidas quanto a serem uma ferramenta analítica nem a como devem ser construídas cientificamente. Este artigo contribui para uma discussão mais profunda acerca da importância de analisar as intervenções, iniciativas, programas e projetos, a fim de serem consideradas ou não boas práticas. Por isso, muitas vezes recorremos à utilização de outros conceitos como intervenções, iniciativas, programas, projetos, práticas, numa tentativa de não abusar do termo boa prática, para que seja utilizado quando um caso for estudado, analisado e avaliado.

Consideramos que a principal contribuição do presente trabalho é permitir a discussão acerca da metodologia de boa prática no caso concreto da Unidade Móvel de Saúde da Venda Nova. Tentámos, na medida em que o espaço nos permitiu, aprofundar os aspetos pouco estudados e debatidos, especialmente o dos valores que se relacionam com as boas práticas em si e com a sua avaliação, e sobre como se exerce e articula o poder no processo de planificação e avaliação das denominadas boas práticas. Constatámos assim que a intervenção e a avaliação das boas práticas em matéria de saúde e imigração não são atividades alheias às dinâmicas de poder entre os diversos atores envolvidos (profissionais da saúde, imigrantes, mediadores interculturais, trabalhadores sociais, responsáveis políticos, organizações não governamentais, associações de imigrantes, institutições e agências de financiamento, etc.).

Ao mesmo tempo, ressaltamos a importância de refletir sobre o papel do poder no processo de identificar as boas práticas e questionamos se é uma atividade científica ou política, ou a conjugação de ambas. Falta-nos contudo refletir sobre quais são as consequências da identificação das boas práticas, quer para as instituições que as possuem, quer para aquelas que delas carecem. No actual contexto de crise, quais são as implicações da utilização das boas práticas? Poderemos questionar-nos se correrão perigo ou se, em consequência da diminuição dos fundos estatais, não nos iremos confrontar num futuro próximo com iniciativas paliativas, levadas a cabo pelas ONG, especialmente de caridade, numa tentativa de darem resposta e cobrirem as necessidades insatisfeitas, substituindo as obrigações de um Estado que delas se demite.

Finalmente gostaríamos de chamar a atenção para um aspeto que reflete a realidade portuguesa. Referimo-nos aqui à riqueza de projetos, iniciativas, práticas levados a cabo no campo da saúde materno-infantil, visto como um sector de enorme vulnerabilidade. Tais intervenções abarcam um universo muito complexo, apresentando uma grande diversidade de respostas que vão desde programas de caráter mais biomédico (campanhas de vacinação, prevenção de infeções de transmisssão sexual, controle prénatal, etc.) até programas de cariz mais social destinados às mães adolescentes, de parentalidade, a apoio material (roupas, leite, carrinhos de bebé). Não podemos contudo avaliar todas as intervenções ou práticas como se de boas práticas se tratassem somente porque se destinam às populações vulneráveis, como o caso das grávidas ou das crianças. Em muitos casos verifica-se esta tendência, o que de facto vem ao encontro do que aqui propusemos.

49 As boas práticas não devem ser encaradas como receitas mas sim como modelos de intervenção tão diversos como diversas são as comunidades. Como tal, torna-se 
importante identificar os princípios nos quais se baseia a intervenção, identificar as estratégias que resultam eficazes, entender como se relacionam as dinâmicas de poder, como se envolve a comunidade interessada, para poder depois determinar se uma prática é efetivamente boa.

\section{BIBLIOGRAFIA}

ASPINAL, P. e B. Jacobson (2004), Ethnic Disparities in Health and Health Care: A Focused Review of the Evidence and Selected Examples of Good Practices, Report London Health Observatory. Disponível em: http://www.lho.org.uk/viewResource.aspx?id=8831

CHINMAN, M., P. Imm \& A. Wandersman (2004), Getting to outcomes 2004. Promoting accountability through methods and tools for planning, implementation and evaluation. RAND Corporation. Em http:// www.rand.org/pubs/technical_reports/TR101.html, consultado a 10 de Janeiro de 2009.

CSDH (2008), Closing the gap in a generation: health equity through action on the social determinants of health. Final report of the Commission on the Social Determinants of Health. Geneva, World Health Organization. Em http://www.who.int/social_determinants/ thecommission/finalreport/en/index.html, consultado em 26 de Agosto de 2010.

EUROPEAN COMMISSION (2008), Quality and Equity of Access to Healthcare Services, DirectorateGeneral for Employment, Social Affairs and Equal Opportunities.

FERNANDES, A. e J. Pereira Miguel (2009), Health and migration in the European Union: Better health for all in an inclusive society, Lisboa, Instituto Nacional de Saúde Doutor Ricardo Jorge.

HERNÁNDEZ-PLAZA, S. et al. (2010), "New settlement and well-being in oppressive contexts: A liberation psychology approach", in S. Carr (Ed.), The psychology of global mobility, Series: International and Cultural Psychology, Vol. 0, Nova Iorque, Springer, pp. 235-256.

MACHADO, M. C. et al. (2009), Maternal and child healthcare for immigrant populations, Background paper, Developed within the framework of the IOM project: "Assisting Migrants and Communities (AMAC): Analysis of social determinants of health and health inequalities", Brussels, International Organization for Migration.

MIPEX (2011), Migrant Integration Policy Index (web-site), Brussels, British Council and Migration Policy Group. Em http://www.mipex.eu/, consultado a 31 de Outubro de 2011.

PADILLA, B. (2011), Health against poverty in Europe. Focus on child, women and older retired migrants from third national countries, Technical Report of the Third Transnational Workshop "Healthy and Wealthy Together: Developing common European modules on migrants health and poverty", INTI Programme, European Fund for the Integration of Third-Country Nationals, European Commission.

PADILLA, B. e R. Portugal (2007), “Saúde e migrações: boas práticas na União Europeia”, in S. Dias (org.), Revista Migrações - Número Temático Imigração e Saúde, Setembro 2007, n.ำ 1, Lisboa: ACIDI, pp. 143-153. 
PADILLA, B. et al. (2009), "Health and migration in the European Union: Good practices", in A. Fernandes \& J. Pereira Miguel (eds.), Health and migration in the European Union: Better health for all in an inclusive society, Lisboa, Instituto Nacional de Saúde Doutor Ricardo Jorge, pp. 101-115.

PRILLELTENSKY, I. (2003), “Understanding, resisting and overcoming oppression: Towards psychopolitical validity”, American Journal of Community Psychology, 29, 747-778.

PRILLELTENSKY, I. (2008), “The role of power in wellness, oppression, and liberation: The promise of psychopolitical validity”, Journal of Community Psychology, 36 (2), 116-136.

SEKN (2008), Understanding and tackling social exclusion. Final report to the WHO Commission on Social Determinants of Health from the Social Exclusion Knowledge Network. Geneva, World Health Organization. Em http://www.who.int/social_determinants/knowledge_networks/ final_reports/sekn_final\%20report_042008.pdf, consultado em 15 de Fevereiro de 2011.

STEGEMAN, I. e C. Costongs (2004), Promoting social inclusion and tacking health inequalities in Europe - An overview of good practices from the health field, EuroHealthNet, Bruxelas.

TRUONG, T.-D. (2006), Poverty, Gender and Human Trafficking. Rethinking Best Practices in Immigration Management, Paris, UNESCO. Disponível em: http://unesdoc.unesco.org/images/ 0014/001432/143227e.pdf.

WHO (2010), How health systems can address health inequalities linked to migration and ethnicity, Copenhagen, WHO Regional Office for Europe. Em http://www.euro.who.int/__data/assets/ pdf_file/0005/127526/e94497.pdf, consultado a 20 de Janeiro de 2011.

\section{NOTAS}

1. Financiado pelos projectos: PTDC/CS-SOC/113384/2009 (FCT) e PsySPOCUC 272976-Marie Curie Action (CE).

\section{RESUMOS}

Nos últimos anos o uso das boas práticas em todas as esferas políticas tem sido uma constante, estendendo-se a vários âmbitos, nomeadamente ao da saúde e das migrações. É curioso verificar, no entanto, que o desenvolvimento teórico nesta matéria se encontra aquém do seu uso. Quais são as consequências do excessivo uso das boas práticas na investigação e na aplicação das políticas relativas à saúde e migrações? É possível transformar o recurso das boas práticas numa ferramenta útil? Em caso afirmativo, que elementos são necessários? Como tem decorrido este processo em Portugal? Traduz-se realmente numa melhoria da saúde dos imigrantes? Através da análise de alguns casos específicos no âmbito da saúde materno-infantil e da chamada competência cultural, tentaremos responder a estas questões teórico-práticas.

Lately, the use of good practices in all policy fields seems to be a constant practice, reaching out to the field of health and migration. However, it is curious to verify that its theoretical development has not advanced as much. What are the consequences of the excessive use of good practices in research and in its aplication to policies regarding health and migration? Is it 
possible to transform the use of good practices in a useful tool? In case it is, what are the necessary elements? How has this process developed in Portugal? Has it meant an improvement in the health of migrants? Through analysing specific cases in the field of maternal and child health and cultural competence, we try to answer to these theoretical and practical inquiries.

ÍNDICE

Keywords: migration, good practices, maternal child health, needs assessment

Palavras-chave: migrações, boas práticas, saúde materno-infantil, avaliação de necessidades

\section{AUTORES}

\section{BEATRIZ PADILLA}

Centro de Investigação e Estudos de Sociologia do Instituto Universitário de Lisboa (CIES-IUL) (padilla.beatriz@gmail.com)

\section{SONIA HERNÁNDEZ-PLAZA}

Centro de Investigação e Estudos de Sociologia do Instituto Universitário de Lisboa (CIES-IUL) (sonia.h.plaza@gmail.com)

\section{ALEJANDRA ORTIZ}

Centro de Investigação e Estudos de Sociologia do Instituto Universitário de Lisboa (CIES-IUL) (aleortizscaglione@gmail.com) 